\title{
KARAKTERISTIK TURBIN PROPELLER SUMBU HORISONTAL PEMBANGKIT LISTRIK TENAGA ARUS LAUT
}

\author{
W. M. Rumaherang ${ }^{1}$, R. Ufie ${ }^{2}$, Wattimena W.M.E ${ }^{3}$, Tentua B. $\mathbf{G}^{4}$ \\ E-mail: ${ }^{1}$ max.rumaherang@,fatek.unpatti.ac.id, ${ }^{3}$ wmewattimena273@gmail.com, ${ }^{4}$ goljintentua@yahoo.com \\ 1,2,3,4 Jurusan Teknik Mesin, Fakultas Teknik Universitas Pattimura, Kampus Poka-Ambon, 97233, Indonesia
}

\begin{abstract}
ABSTRAK
Wilayah kepulauan memiliki potensi arus laut yang dapat dikonversi menjadi energy listrik. Konversi energy ini dapat dilakukan dengan menggunakan turbin. Dalam penelitian ini diaplikasikan turbin propeller horizontal, yang dipasang pada suatu kanal berbentur tabung ventury yang diinstal pada sebuah bangunan terapung. Variasi kecepatan arus laut pada inlet tabung ventury berkisar antara $0,2-2,54 \mathrm{~m} / \mathrm{s}$ pada luas penampang $13,3 \mathrm{~m} 2$. Fluks/densitas daya yang tersedia $0,02-49,5 \mathrm{~kW} / \mathrm{m} 2$. Didalam kanal tabung ventury kecepatan yang masuk ke impeller V1 (inlet propeller) antara 1,2-14,9 m/s., dengan diameter impeller D1 =1,5 m. Putaran refence turbin adalah 23,7 rpm sesuai dengan nilai putran spesifik turbin. Daya yang dibangkitkan turbin berkisar dari 0,25-449 kW dengan efesiensi maksimum $45 \%$.
\end{abstract}

Kata kunci : Turbin Propeller, Arus Laut, Blade Impeller, Tabung Venturi.

\section{PENDAHULUAN}

Ketersediaan energi merupakan isu penting yang difokuskan pada tiga tujuan utama, yakni pembangunan ekonomi, ekology dan sosial masyarakat sekaligus merupkan upaya mendukung RE-BID (Renewable Energy Based on Indistrial Development). Pemanfaatan EBT sebagai sumber energy merupakan solusi terbaik dalam penyediaan energi.

Sifat fisik energy kinetik arus laut pada beberapa wilayah dapat memberikan peluang untuk dikonversi menjadi energi listrik. Dari 727 GW potensi energy arus laut Indonesia, 4,8 GW diantaranya dapat dimanfaatkan secara praktis (Harkins H. Prabowo \& Susilohadi, 2014). Demikian pula selat antara pulau-pulau kecil memiliki kecepatan arus mencapai $2,4 \mathrm{~m} / \mathrm{s}$, dapat dikonversikan menjadi energi listrik (Tim peneliti Fakultas Teknik 2015).

Turbin yang digunakan untuk mengkonversi energy arus laut terdiri dari turbin aksial sumbu horizontal (F. L. Fraenkel, 2010) dan turbin crosflow (A Roberts, et al., 2016)

Turbin axial saat ini merupakan turbin yang lebih popular penggunaannya dalam perencanaan turbin pada PLTAL (A Roberts, et al. 2016).

Karakteristik turbin merupakan hubungan parameter-parameter energy terhadap perubahan kecepatan aliran arus laut. Dalam penelitian ini, dikembangkan floating turbine tipe ventury kapsul propeller. Umumnya densitas energi arus laut dengan menggunakan persamaan Fraenkel untuk aliran terbuka. Namun dalam penelitian ini dianalisa aliran melalui tabung ventry yang dapat menaikan kecepatan aliran yang menggerakan impeller turbin.

\section{KAJIAN TEORI DAN METODE}

\section{Teori Energi Arus Laut Pasang}

\section{- Kondisi Arus Laut pada beberapa SPOT di Maluku}

Hasil pengukuran menunjukan kecepatan mencapai $2,25 \mathrm{~m} / \mathrm{s}$, untuk pada titik-titik yang dilalui alat ukur. Kecepatan arus pada setiap titik pada traject ditunjukan pada gambar 1 .

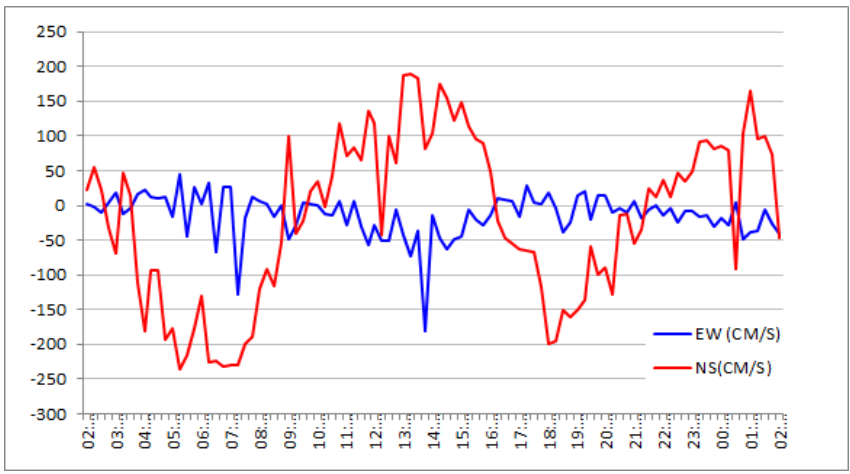

Gambar 1. Batimetri dan kecepatan Arus harian pada Selat Haya Selat Haya

Vektor kecepatan arus pada lokasi selat Haya ditunjukan pada gambar 2 untuk proses menuju pasang dan menuju surut. 

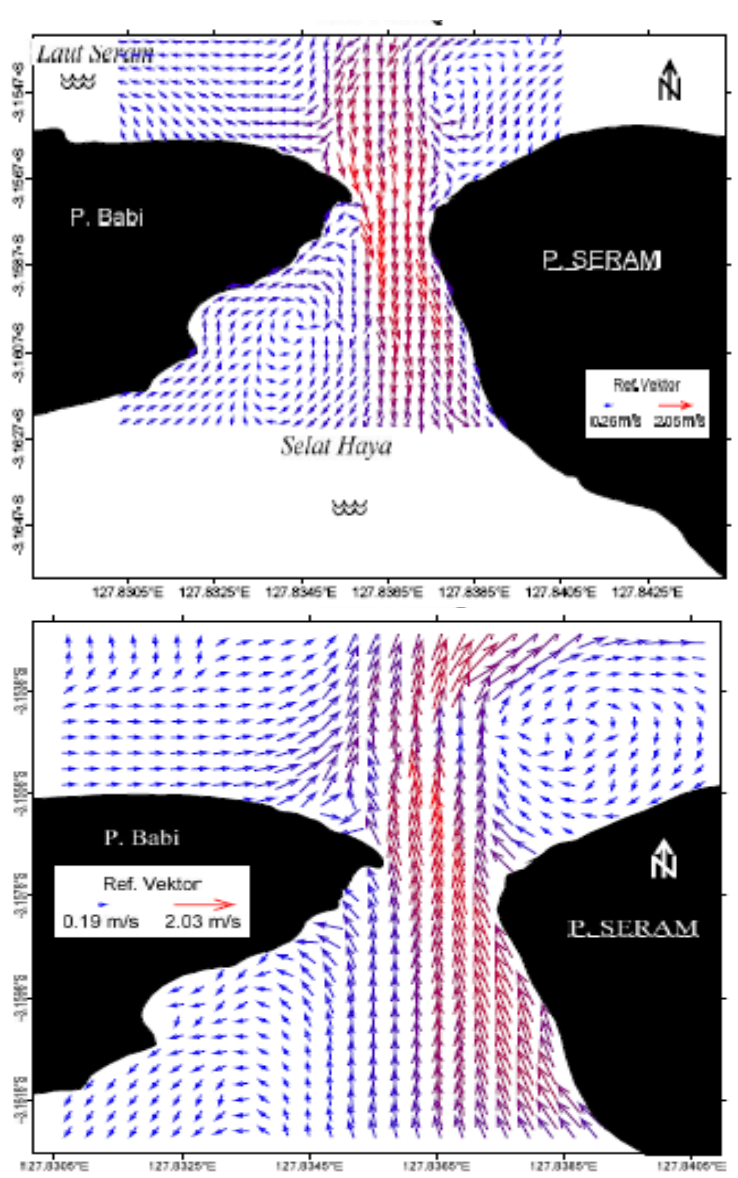

Gambar 2. Vektor arus pada lokasi selat Haya Sumber : Laporan Tim Peneliti Universitas Pattimura

\section{- Enegri Arus Laut (Tidal Energy)}

Pasang surut adalah proses naik turunnya muka laut secara hampir periodik karena gaya tarik bulan dan matahari. Naik turunnya muka laut dapat terjadi sekali sehari (pasut tunggal), atau dua kali sehari (pasut ganda). Sedangkan pasut yang berperilaku di antara keduanya disebut sebagai pasut campuran (Dahuri et all, 2004).

Arus laut mempunyai kecepatan rata-rata lebih rendah dari kecepatan angin, namun densitasnya lebih tinggi sehingga menjamin daya yang tersedia untuk dikonversi oleh turbin dengan daya yang sama dengan turbin angin (Bahaj and Myers 2003). Tidak ada aliran arus laut yang ekstrim sehingga aman terhadap kerja dan tidak merusak peralatan (Blunden and Bahaj 2006). Namun konstruksi peralatan turbin arus laut harus dapat menahan beban gaya dari air yang besar dalam waktu lama dan mencakup perbedaaan bilangan Reynolds, fenomena kavitasi dan arah bolak balik dari arus pasang surut (Garrett and Cummins 2004, Whelan et al. 2009).
Daya puncak turbin yang diperoleh dari satu aliran fluida tak terhingga yang dapat dijelaskan secara matematika menggunakan teori momentum (A Roberts, et all 2016), yang disebut persamaan Fraenkel (Tonny AdamTheoyana, et all, 2015):

$$
P=\frac{1}{2} \rho A C_{P} U_{\infty}^{3}
$$

Densitas atau flux daya dari aliran arus laut (daya yang dihasilkan per $\mathrm{m}^{2}$ luas penampang melintang arus laut).

$$
P_{d}=\frac{P}{A}=\frac{1}{2} \rho C_{p} U_{\infty}^{3}
$$

Dimana $\mathrm{C}_{\mathrm{p}}=$ koefesien turbin, densitas air laut $\rho 1025 \mathrm{~kg} / \mathrm{m}^{3}$ dan $U_{\infty}$ adalah kecepatan air laut. Untuk luas aliran pada turbin axial, batasan ini adalah 59,3\% (16/27) (Lanchester 1915; Betz 1966).

\section{- Energy spesifik Aliran}

Pada tulisan ini dilakukan perancangan dan pengujian turbin arus laut sumbu horizontal dalam sebuah tabung venture. Energi spasifik turbin didefinisikan sebagai [7],

$$
\begin{aligned}
E=g H= & \frac{1}{\rho}\left(p_{1}-p_{2}\right)+\frac{1}{2}\left(c_{1}^{2}-c_{2}^{2}\right)+ \\
& g \cdot\left(z_{1}-z_{2}\right)
\end{aligned}
$$

Dimana : $\mathrm{gH}=$ specific hydraulic energy machine $[\mathrm{J} / \mathrm{kg}], \mathrm{p}_{\mathrm{x}}=$ tekanan pada penampang $\mathrm{x}$ $[\mathrm{Pa}], \mathrm{c}_{\mathrm{x}}=$ kecepatan air pada penampang $\mathrm{x}$ $[\mathrm{m} / \mathrm{s}], \mathrm{z}_{\mathrm{x}}=$ elevation penampang $\mathrm{x}[\mathrm{m}]$.

Index 1 and 2 adalah lambang ukuran pada sisi upstream and downstream diukur dari sumbu turbine. Head neto (net head) didefinisikan sebagai :

$$
H_{n}=\frac{E}{g}
$$

\section{- Parameter Energi Turbin}

Daya air (hydraulic power) turbin diberikan oleh persamaan :

$$
P_{w}=\rho g Q_{h} H
$$

Dimana : $\quad P_{w}=$ Daya yang tersedia $(\mathrm{kW})$. $\rho Q=$ Laju aliran massa air $[\mathrm{kg} / \mathrm{s}]$.

$\rho=$ densitas air laut $[\mathrm{kg} / \mathrm{m}]$.

$\mathrm{Q}=$ Kapasitas aliran $[\mathrm{m} / \mathrm{s}]$.

$\mathrm{g}=$ percepatan gravitasi $[\mathrm{m} / \mathrm{s}]$.

$\mathrm{H}=$ head neto [m]. 
Daya turbin aliran terbuka dihitung dengan menggunakan persamaan (1). Dari penyelesaian persamaan Bernoulli untuk aliran relative pada titik 1 dan titik 2 yang terletak pada satu garis alir di depan dan di belakang impeller diperoleh:

$$
\frac{g H_{T}}{\omega}=\left(r V_{u}\right)_{1}-\left(r V_{u}\right)_{2}
$$

Dimana $H_{T}=\eta H_{n}$, dimana $H_{n}-$ head netto, $\eta$ efisiensi hidrolis.

Momen putar diperoleh perbedaan nilai tekanan lokal di sisi tekan dan sisi isap pada penampang meridian impeller:

$$
M_{x}=\int \Delta \operatorname{prd} S_{1}
$$

Dimana: $\Delta p=p_{p}-p_{m}$ - adalah jatuh tekanan pada permukaan elementar $\mathrm{dS}_{1}$ pada proyeksi blade pada penampang meridian, $\mathrm{S}_{1}$ - proyeksi blade pada penampang meridian.

Dari perhitungan segitiga kecepatan, dihitung momen putar, sehingga daya pada poros turbin adalah:

$$
P_{p}=M x \cdot \omega=\rho g H_{T} Q
$$

Dimana $P_{p}$ - Daya yang dihasilkan $(\mathrm{kW}), \omega-$ kecepatan sudut impeller $(\mathrm{rad} / \mathrm{s}), \mathrm{H}_{\mathrm{T}}-\mathrm{Head}$ teoritis hidroturbin.

Efisiensi turbin didefinisikan sebagai :

$$
\eta=\frac{P_{p}}{P_{w}}
$$

\section{- Type dan ukuran}

Pemilihan tipe, geometri and dimensidimensi turbin akan ditentukan berdasarkan kriteria teknis yaitu head neto $(\mathrm{H})$, renge kapasitas $\mathrm{Q}$ yang melalui turbine, kecepatan, $n_{Q E}$, (rpm), masalah-masalah kavitasi. Type turbin ditentukan berdasarkan kecepatan spesifik impeller turbine yang dihitung dengan persamaan

$$
n_{Q E}=\frac{n \cdot \sqrt{Q}}{E^{3 / 4}}
$$

Dimana: $\mathrm{Q}=$ Kapasitas aliran $\left(\mathrm{m}^{3} / \mathrm{s}\right)$, $\mathrm{E}=$ energi hydraulik specifik turbin $(\mathrm{J} / \mathrm{kg})$, $\mathrm{n}=$ putaran $[\mathrm{rps}]$.

Secara khusus untuk head rendah (low head) diaplikasikan turbin reaksi. Turbin Kaplan dengan pitch blade yang dapat diatur (adjustable blade) mudah diadaptasikan pada luasan range aliran atau head, sehingga efisiensi puncaknya dapat mencapai diatas luasan range kondisi aliran.
Karena itu dalam penelitian ini type turbin yang dipilih adalah turbin horizontal kapsul propeller.

\section{- Penentuan ukuran turbin}

Bedasarkan kebutuhan daya yang dibangkitkan oleh fluida, maka dimensi dan geometri turbin diperoleh melalui persamaan konitutas aliran. Di dalam turbin aliran melewati tiga penampang utama: penampang pipa inlet $\mathrm{A}_{0}$, penampang bulb sudu pengarah $\mathrm{A}_{\mathrm{g}}$ dan penampang di impeller $A_{1}$. Kecepatan meridian pada masing-masing penampang adalah $\mathrm{V}_{\mathrm{m}, 0}$, $\mathrm{V}_{\mathrm{m}, \mathrm{g}}$ dan $\mathrm{V}_{\mathrm{m}, 1}$.

Diameter impeller ditentukan oleh kecepatan aliran fluida pada penampang meridian $\left(V_{m}\right)$ dan debit $(Q)$. Dengan menetapkan luas $\mathrm{A}_{1}$, selanjutnya dihitung diameter impeller $\mathrm{D}_{1}$. Dari perhitungan konstruksi dan kekuatan poros, maka adalah:

$$
V_{m, 1}=V_{x, 1}=\frac{4 Q}{\pi D_{1}^{2}\left(1-\bar{d}_{b s}^{2}\right)}
$$

Dimana $\quad \bar{d}_{b s}=\frac{d_{b}}{D_{1}}=$ perbandingan bosch impeller; $\mathrm{D}_{1}=$ diameter impeller.

Selanjutnya dari nilai $\mathrm{D}_{1}$ dapat ditentukan putaran impeller. Ukuran overall turbine akan dihitung berdasarkan ukuran $\mathrm{D}_{1}$.

Dalam penelitian ini dikaji turbin prpopeller sumbu horsontal yang dipasang dalam sebuah tabung venturi. Tabung ventury dinstal pada sebuah stasiun terapung.

Kecepatan arus laut diukur dengan bantuan floating current meter (drifter trajectories) pada setiap level pasang surut. Parameter-parameter aliran dalam turbine diuji melalui model matematika berbasis metode analitik dan numerik dengan menyelesaikan persamaan diferensial dan integral pada kondisi-kondisi batas system sesuai sifat-sifat aliran yang terjadi. Perhitungan karakteristik hidrodinamika turbin dilakukan dengan metode numerik berbasis CAD untuk sistem blade dan ventury system. Parameterparameter energi digambarkan dalam dalam kurva karakteristik yaitu hubungan parameter daya dan efesiensi turbin terhadap perubahan kecepatan aliran $\mathrm{Vo}_{0}=0.2 \div 1 \mathrm{~m} / \mathrm{s}$ untuk geometri turbin konstan. 


\section{HASIL DAN PEMBAHASAN}

\section{- Densitas Daya}

Kecepatan arus harian pada lokasi Selat Haya (dua siklus pasang surut) ditunjukan pada gambar 4.9. Lama waktu pergerakan arus adalah \pm 6 jam dengan keepatan $0.5 \mathrm{~m} / \mathrm{s}$ sampai dengan $2.25 \mathrm{~m} / \mathrm{s}$ untuk proses menuju surut dan untuk pasang \pm 6 jam dengan kecepatan $0.5 \mathrm{~m} / \mathrm{s} 1.8 \mathrm{~m} / \mathrm{s}$. Arah antara $165^{\circ}$ sampai dengan $175^{\circ}$ (menuju selatan) dengan kedalaman rata-rata 15 metes. Selanjutnya menurut persamaan (1) densitas daya mencapai $5837,695 \mathrm{~W} / \mathrm{m}^{2}$.

Berdasarkan persamaan (1) dengan menerapkan prinsip tabung ventury, maka densitas daya untuk lokasi ini ditampilkan pada gambar 3., dimaan untuk kecepatan arus laut 0,2 $2,54 \mathrm{~m} / \mathrm{s}$, maka flux daya berkisar antara $0,02-$ $49,5 \mathrm{~kW} / \mathrm{m} 2$.

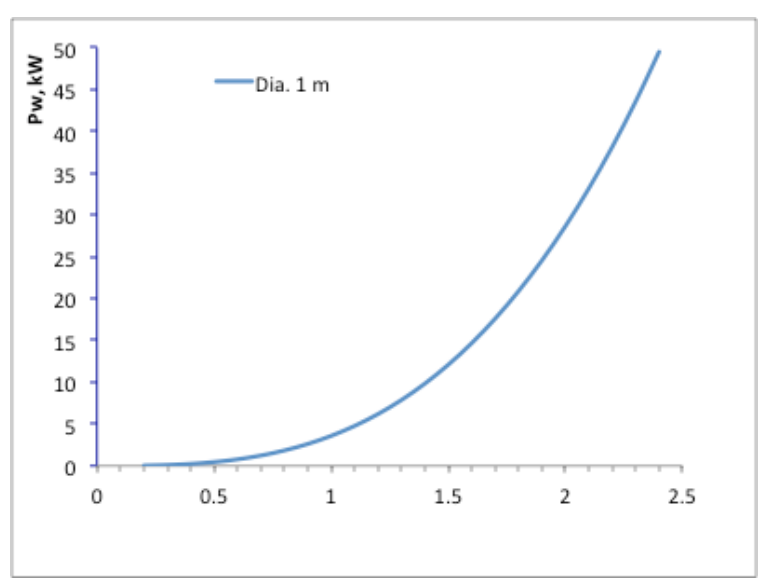

Gambar 3. Densitas daya dia. inlet turbin $1 \mathrm{~m}$.

\section{- Parameter-Parameter Energy Turbin.}

Turbin didesign dan diuji dengan menggunakan system floating, yaitu dengan menempatkan turbin dibawah bangunan terapung atau ponton. Sistem turbin ditunjukan dalam gambar 4.

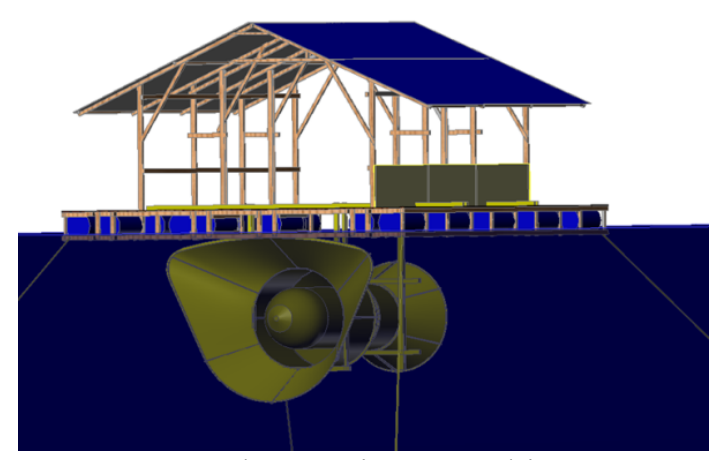

Gambar 4. Sistem Turbin
Dalam penelitian ini dikembangkan sebuah turbin axial propeller horizontal yang pasang pada sebuah tabung venturi, yang dimaksudkan untuk meningkatkan kecepatan aliran sampai 2 kali kecepatan arus laut.

Design prototype terdiri dari Intake dan draft tube, rumah stator, kapsul generator, dan impeller dan sistem transmisi.

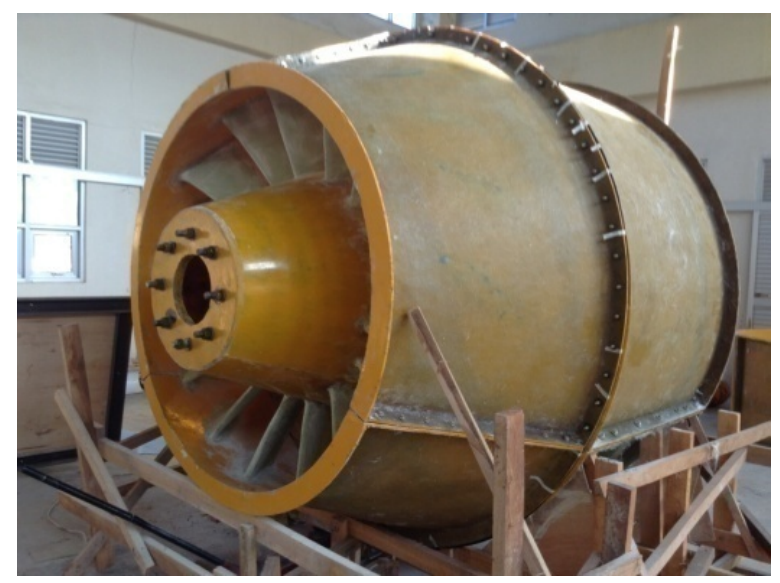

Gambar 5. Konstruksi Turbin

Turbin didesain agar dapat beroperasi pada kecepatan 0,2 sampai dengan $1,0 \mathrm{~m} / \mathrm{s}$. Titik rancang pada kecepatan rata-rata pengujian $\mathrm{V}_{0}$ $=0,5 \mathrm{~m} / \mathrm{s}$, dengan debit aliran $6,585 \mathrm{~m}^{3} / \mathrm{s}$. Momen yang dibutuhkan turbin adalah $\mathrm{Mz}=18914 \mathrm{~N}$ dengan putaran turbin rata-rata adalah $\mathrm{n}=23,7$ rpm. Dengan demikian diameter inlet dirancang sebesar 4,095 $\mathrm{m}$ dengan luas penampang 13,17 $\mathrm{m}^{2}$.

Dari persamaan (9) diperoleh rata-rata head sebesar $0.5 \mathrm{~m}$. Namun untuk mendapatkan putaran diatas, maka kecepatan aliran yang masuk ke impeller dibutuhkan sebesar $5 \mathrm{~m} / \mathrm{s}$. Sehingga menurut persamaan (10) dengan diameter 1,5 meter dan jumlah sudu 4 buah (gambar 6).

Pengujian Turbin dilakukan daam 2 cara, yaitu dengan menggunakan method CFD untuk melukiskan performance hydrodinamiknya dan pengujian prototype pada lokasi yang ditetapkan. 

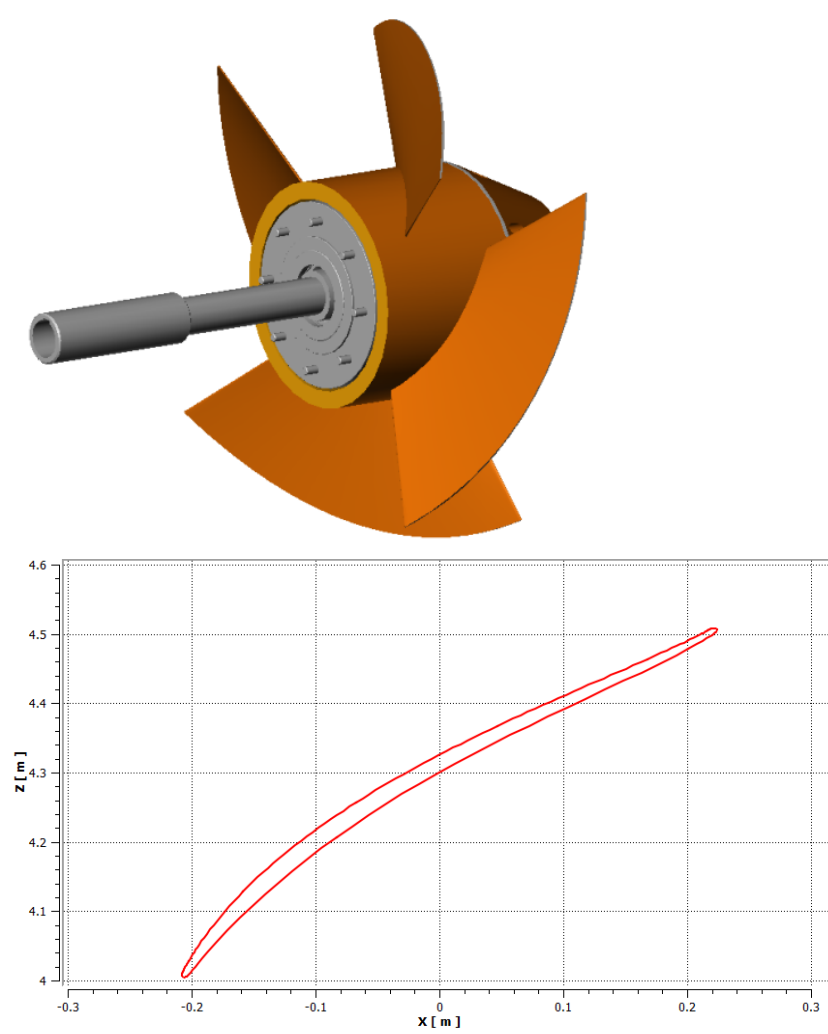

Gambar 6. Konstruksi dan profil blade impeller.

Momen putar (pers. 6) dan daya yang dihasilkan pada poros (pers 7) untuk berbagai perubahan kecepatan arus laut ditunjukan pada kurva karakteristik turbin gambar 7. Dimana daya yang dibangkitkan turbin berkisar dari 0,25 - 449 $\mathrm{kW}$ untuk kecepatan awal $0,2-2,54 \mathrm{~m} / \mathrm{s}$ untuk luas penampang inlet $A o=13,3 \mathrm{~m} 2$ atau pada kecepatan V1 (inlet propeller) antara 1,2 - 14,9 $\mathrm{m} / \mathrm{s}$.

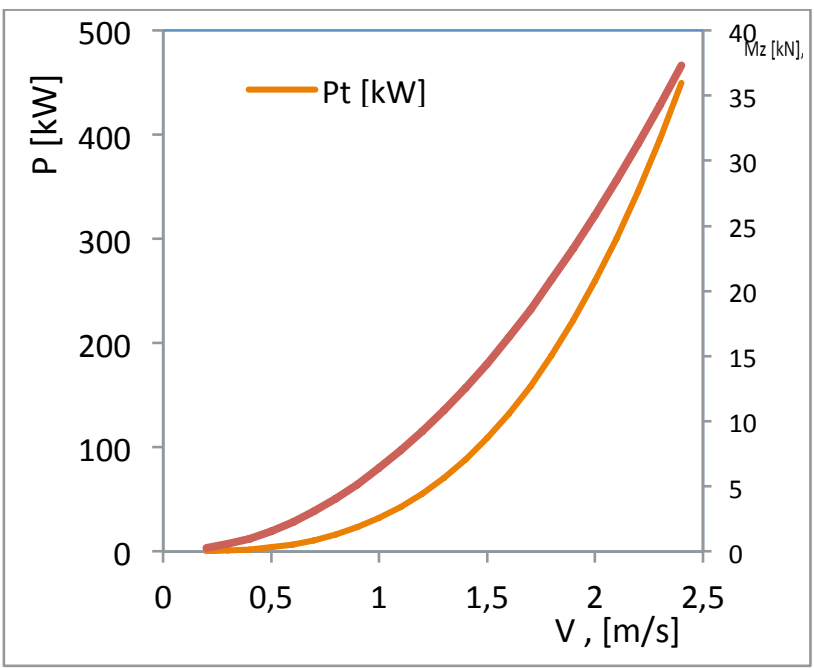

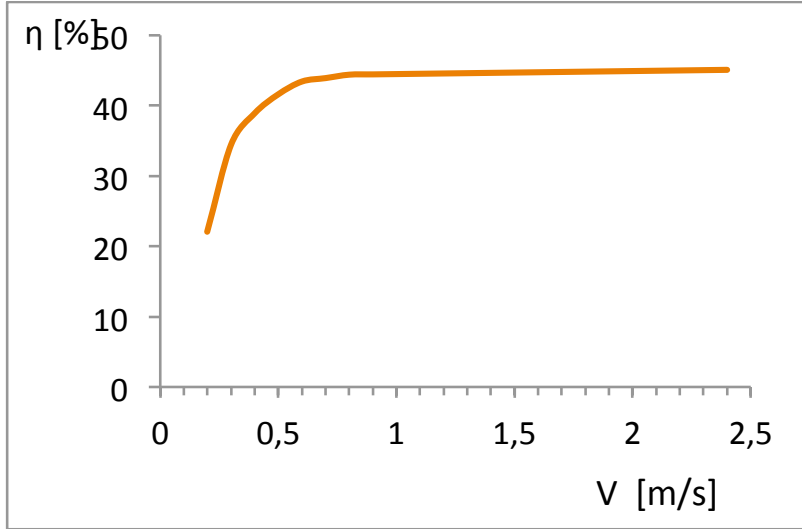

Gambar 7. Karakteristik Turbin

\section{KESIMPULAN}

Dari hasil pembahasan dapat dibuat kesimpulan sebagai berikut:

1. Untuk kecepatan spesifik yang tinggi atau head rendah digunakan turbin propeller horizontal.

2. Untuk meningkatkan Head turbin maka kecepatan aliran harus ditingkatkan dengan menggunkan prinsip tabung ventury, sehinggan kecepatan aliran yang masuk ke impeller menjadi 1,2 sampai 14 $\mathrm{m} / \mathrm{s}$ dengan daya $0,25-449 \mathrm{~kW}$.

\section{DAFTAR PUSTAKA}

A. Roberts, B. Thomas, P. Sewell, Z. Khan, S. Balmain, J. Gillman. (2016). Current Tidal Power Technologies And Their Suitability For Applications In Coastal And Marine Areas, Journal Of Ocean Engineering and Marine Energy No 2 PP 227-245

Harkins H. Prabowo \& Susilohadi. (2014), Summary Of Mapping And Modelling Ocean Current Energy In Potential Straits In Indonesia, Center For Research And Development Of Marine Geology Energy And Minerals Resources Research And Development Agency Ministry Of Energy And Mineral Rsources, R.I.

IHI Cooporation (2014). Power Generation Using the Kuroshio Current. Development of floating type ocean current turbine system. IHI Engineering Review Vo 1. 46 No. 2 PP 1-5

P. L. Fraenkel (2010), Development and testing of Marine Current Turbine's SeaGen 1.2MW tidal stream turbine, 3rd International Conference on Ocean Energy, 6 October, Bilbao, 2010. 
Tonny Adamtheoyana, Et All (2015). Potensi Energi Arus Laut Pada Berbagai Kedalaman Untuk Pembangkit Listrik Di Selat Badung, Bali, Jurnal Oseanografi. Volume 4, Nomor 1, PP $262-269$.

Yun Seng, Liem, Shiong Lee, Koh. (2009). Marine Tidal Electric Power Generation:State of Art and Current status, Journal Of Renewable energy Intech.

Yu-Chia Chang, Peter C. Chu, Ruo-Shan Tseng, (2015). Site selection of ocean current power generation from drifter measurements. Renewable Energy No 80 PP 737-745 International Journal Elsevier. 